\title{
Updated North Cyprus response status for COVID-19 in comparison with similar country sizes. Highlights on the importance of population per square meter
}

\author{
Nedime Serakinci, ${ }^{1,2}$ Ahmet Savasan, ${ }^{3}$ Finn Rasmussen ${ }^{4,5}$ \\ ${ }^{1}$ Department of Medical Genetics, Faculty of Medicine, Near East University, Lefkosa, Nicosia, Cyprus \\ ${ }^{2}$ Department of Molecular Biology of Genetics, Arts and Sciences Faculty, Near East University, Lefkosa, Nicosia, Cyprus \\ ${ }^{3}$ Arts and Sciences Faculty, Near East University, Lefkosa, Nicosia, Cyprus \\ ${ }^{4}$ Department of Allergy Sleep and Respiratory Medicine, Near East University Hospital, Near East University, Lefkosa, \\ Nicosia, Cyprus \\ ${ }^{5}$ Department of Internal Medicine, Section of Respiratory Medicine, Sydvestjysk Hospital, Denmark
}

\begin{abstract}
The COVID-19 pandemic is straining health systems worldwide. The World Health Organization has provided guidelines on a set of targeted and immediate actions that countries can use on a national, regional, and local level. Recommendations go from public hand hygiene stations, making face masks use obligatory, testing, and index finding which together with national closure of borders have been used to limit the disease so the countries' health care system can cope with the challenges. This is especially important as there seems to be an increased mortality rate even in countries normally regarded as well-functioning and having strong health system. In more susceptible countries this maybe even more important. The effect of these measures should be easier seen in small communities or countries. Societies have acted differently on when to apply the lockdown but most European countries have initiated lockdown after the first SARS-CoV-2 was diagnosed in their countries. With the COVID-19 pandemic and its economic consequences, it became especially important to re-evaluate the effect of response in light of a possible second wave. Yet, little is known about the effect of lockdown with respect to disease development and its handling. Hereby, we compare responses from relatively small 17 European countries including islands in three groups based on their population and report the response from North Cyprus in comparison to other small European countries. Our results indicate the importance of population per meter square, degree of isolation from others as well as social distancing, hygiene rules, timing of lockdowns in response to COVID-19 pandemic in small countries/ societies that are more susceptible for overwhelming their health system.
\end{abstract}

Key words: COVID-19; TRNC; SARS-CoV-2.

Correspondence: Nedime Serakinci, Department of Medical Genetics, Faculty of Medicine, Near East University, Lefkosa, Nicosia, Cyprus.

E-mail: nedime.serakinci@neu.edu.tr

Contributions: All authors contributed equally to the collection of data, analysis, writing, revising, journal selection and submission

Conflict of interest: The authors declare that there is no competing interest regarding this publication.

Funding: This work did not receive any funding.

Availability of data and materials: Data are available from the corresponding author upon reasonable request.

Ethics approval and consent to participate: As the data is provided by Turkish Republic of Northern Cyprus (TRNC) government, publication consent and ethics approval is not needed. 


\section{Introduction}

Coronavirus disease 2019 (COVID-19) has raised a series of public health problems within a short time and caused many unforeseen challenges whose consequences will be particularly important at all levels across the world. The World Health Organization (WHO) announced the global spread of Severe Acute Respiratory Syndrome Coronavirus 2 (SARS-CoV-2) as a pandemic short after December 2019.

With the identification of the first index case on March $9^{\text {th }}$, the Northern Cyprus government decided to carry out several comprehensive initiatives to control the spread of COVID-19 disease. As it was the case for many other countries, this meant a partial lockdown and all public employees, who do not have a critical function, were asked to stay at home and strongly encouraged to work from home. Educational institutions at all levels including day-care were closed to prevent an overwhelming of the health system.

As the first index case was a German tourist lady, all accompanying tourists were put into quarantine in 3 different hotels. Two days after, the second German tourist was hospitalized, then put into intensive care. Following, week's first local case was identified who was the first SARS-CoV-2 local case for Northern Cyprus, and in all there have been 108 cases. All cases were either within the German tourist group or contacts to the bus driver who had transported the group of people who had arrived from United Kingdom.

Despite the preparation and cautions taken by the government and particularly by the health ministry generally, the clinical presentations of the COVID-19 patients diagnosed in Northern Cyprus were mild. Only 5 were admitted to the intensive care unit and 4 of them died. After the first week, several more restrictions were presented; the border was closed, assemblies of associations, unions, locales and performing collective worship were prohibited and shopping malls, restaurants, hairdressers and several other shops were closed (excluding grocery stores and pharmacies, gas stations, bakeries, butchers, etc.). Two-meter social distancing, and hygiene rules were applied for those who needed to go to these places. Besides the relatively low rate of COVID-19 incidents in the country, the WHO measures to fight and prevent more COVID-19 cases have been taken as part of precautionary principles, thus the government prioritizes to ensure that the health care system was not overwhelmed.

In cooperation with the authorities, the North Cypriots strictly followed the guidelines, such as frequent hand washing, avoiding physical contact, and keeping a two-meter distance from each other.

\section{Methods}

All countries compared with Turkish Republic of Northern Cyprus (TRNC) in this study have a population below 2 million. All governments used isolation, social distancing to block transmission with SARS-CoV-2. Only Greenland did not have a formal lockdown but did isolation of cases. Measures included closing all but essential shops and businesses, obligatory wearing masks in public space, banning gatherings, and instructing people to stay at home except for essential journeys and work [1,2].

Table 1. Duration between the first and last COVID-19 cases in the studied countries.

\begin{tabular}{|c|c|c|c|c|c|c|c|}
\hline Country & $\begin{array}{l}\text { Index case } \\
\text { date }\end{array}$ & $\begin{array}{l}\text { Index case } \\
\text { origin }\end{array}$ & $\begin{array}{r}\text { Lockdown } \\
\text { to }\end{array}$ & $\begin{array}{l}\text { Index case } \\
\text { lockdown (days) }\end{array}$ & $\begin{array}{l}\text { Date of last } \\
\text { new case }\end{array}$ & $\begin{array}{l}\text { Time from first } \\
\text { to last case (days) }\end{array}$ & $\begin{array}{l}\text { Mortality: Dead / } \\
\text { Test positive (\%) }\end{array}$ \\
\hline \multicolumn{8}{|c|}{ Less than 50.000} \\
\hline Vatican City & $5^{\text {th }}$ March & Italy & $8^{\text {th }}$ March & 3 & $7^{\text {th }}$ May & 63 & 0 \\
\hline Gibraltar & $4^{\text {th }}$ March & Italy & $24^{\text {th }}$ March & 10 & 5 active cases & $\infty$ & 0 \\
\hline San Marino & $27^{\text {th }}$ February & Italy & $14^{\text {th }}$ March & 16 & 28 active cases & $\infty$ & 6.0 \\
\hline Liechtenstein & 3rd March & Switzerland & $16^{\text {th }}$ March & 13 & 13 active cases & $\infty$ & 1.2 \\
\hline Monaco & $29^{\text {th }}$ February & & $14^{\text {th }}$ March & 19 & 2 active cases & $\infty$ & 4.0 \\
\hline Faeroe Islands & $4^{\text {th }}$ March & France & $17^{\text {th }}$ March & 13 & $25^{\text {th }}$ April & 52 & 0 \\
\hline \multicolumn{8}{|c|}{50.000 to 100.000} \\
\hline Greenland & $18^{\text {th }}$ March & Denmark & No lockdown & $\infty$ & $19^{\text {th }}$ April & 32 & 0 \\
\hline Andorra & 2nd March & Italy & $13^{\text {th }}$ March & 11 & 7 active cases & $\infty$ & 6.1 \\
\hline Isle of Man & $19^{\text {th }}$ March & United Kingdom & $26^{\text {th }}$ Match & 7 & 3rd June & 75 & 7.1 \\
\hline \multicolumn{8}{|c|}{100.000 to 500.000} \\
\hline Iceland & $28^{\text {th }}$ February & Italy & $13^{\text {th }}$ March & 15 & 8 active cases & $\infty$ & 0.5 \\
\hline TRNC & $10^{\text {th }}$ March & Germany & $10^{\text {th }}$ March & 0 & $18^{\text {th }}$ April & 40 & 3.7 \\
\hline Malta & $7^{\text {th }}$ March & Italy & $13^{\text {th }}$ March & 6 & 40 active cases & $\infty$ & 1.3 \\
\hline \multicolumn{8}{|c|}{500.000 to 1 million } \\
\hline Luxembourg & $29^{\text {th }}$ February & Italy & $15^{\text {th }}$ March & 15 & 54 active cases & $\infty$ & 2.7 \\
\hline Montenegro & $17^{\text {th }}$ March & USA & $24^{\text {th }}$ March & 7 & 38 active cases & $\infty$ & 2.5 \\
\hline \multicolumn{8}{|l|}{1 to 2 million } \\
\hline Estonia & $27^{\text {th }}$ February & Iran & $13^{\text {th }}$ March & 15 & 189 active cases & $\infty$ & 3.5 \\
\hline Cyprus & $9^{\text {th }}$ March & Italy & $13^{\text {th }}$ March & 4 & 35 active cases & $\infty$ & 1.9 \\
\hline
\end{tabular}




\section{Statistics}

For dichotomous variables, non-parametric tests were used. Differences for both tests were considered significant if $p$ was 0.05 or less. Statistical analysis was performed with the IBM Statistical Package for Social Sciences ver. 23 (SPSS Inc., Chicago, IL, USA).

\section{Results}

The index case was found on the $9^{\text {th }}$ of March in the Turkish Republic of Northern Cyprus (TRNC), a female German tourist arrived by plane, and later 30 other foreigners were tested positive for SARS-CoV-2. A bus driver who brought a tourist group in isolation was later the first local person tested positive for SARSCoV-2. A total of 108 cases was found, 31 persons (29\%) were foreigners (Figure 1a). All cases among foreigners were found within 10 days after the index case. The peak of new cases was on day 22 after the index case (Figure 1a). The maximum number of patients admitted to intensive care for COVID-19 was $2(1.8 \%)$. The peak of treatment in the hospital was on the $4^{\text {th }}$ of April with 57 persons (53\%; 26 days after index case). The last person discharge from hospital was on the $5^{\text {th }}$ of May (57 days after index case) and the last person to be declared disease-free was on the $10^{\text {th }}$ of May (62 days after index case). The age distributions of persons with
COVID-19 in TRNC were up to 18 years (14.6\%), between 19-40 years $(25.0 \%)$, above 40 below 60 years $(38,2 \%)$, and 60 to 79 years $(19.3 \%)$, whereas above $80 \%(2.9 \%)$.

The last new case was found on the $18^{\text {th }}$ of April (40 days after index case). This duration between the first and last cases of SARS CoV-2 is like the duration seen in Greenland (Table 1). In TRNC 5 persons had to be admitted to intensive care $(4.6 \%)$ and out of those 4 persons died $(3.7 \%)$. The mortality was the $5^{\text {th }}$ highest mortality rate among the 16 small countries in Europe. In comparison, Cyprus, with a similar demographic and genetic population, had a mortality rate of $1.9 \%$ (dead/test positive). Only 5 (31\%) out the 16 smallest European countries (below 2 mil) were able to have no new SARS-CoV-2 and all had a lockdown within 14 days of the index case (Table 1). The most frequent origin of index cases was from Italy (44\%) (Table 1).

TRNC had the second-lowest number of cases $(309$ cases/mil inhabitants) among the 16 small European countries/territories; only Greenland reported a lover number (209 mil/inhabitants), with Luxembourg presenting far the highest number of cases per mill ( $>4,000 \mathrm{mil} /$ inhabitants) (Figure $1 \mathrm{~b}$ ). The number of tests per mill was the highest in the countries with the lowest population but was not associated with mortality. Among the countries that achieved zero cases, the density was lower than those which did not achieve zero cases $\mathrm{p}<0.05$ (Figure 1c). a

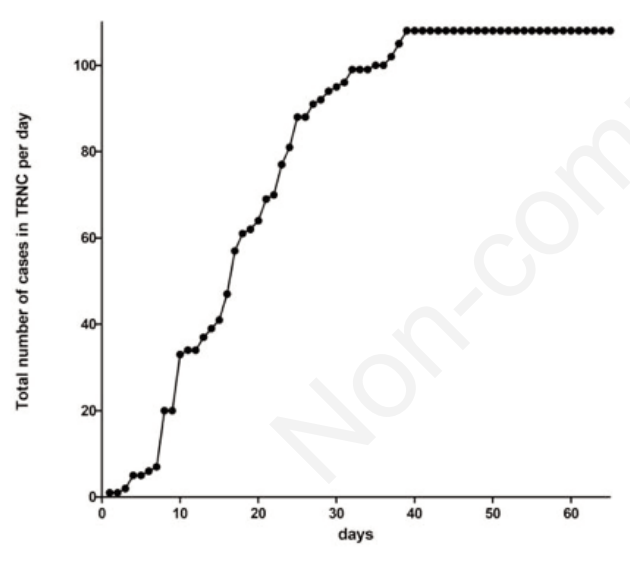

C

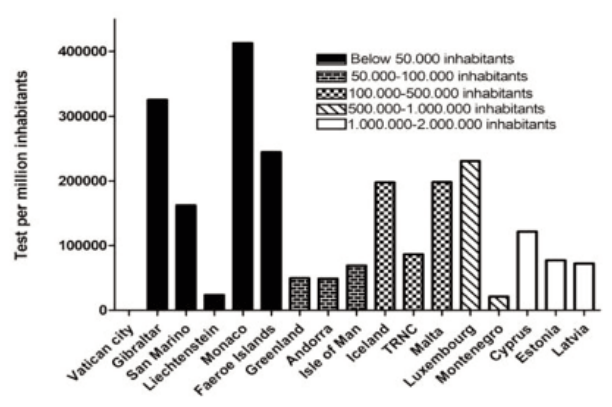

b
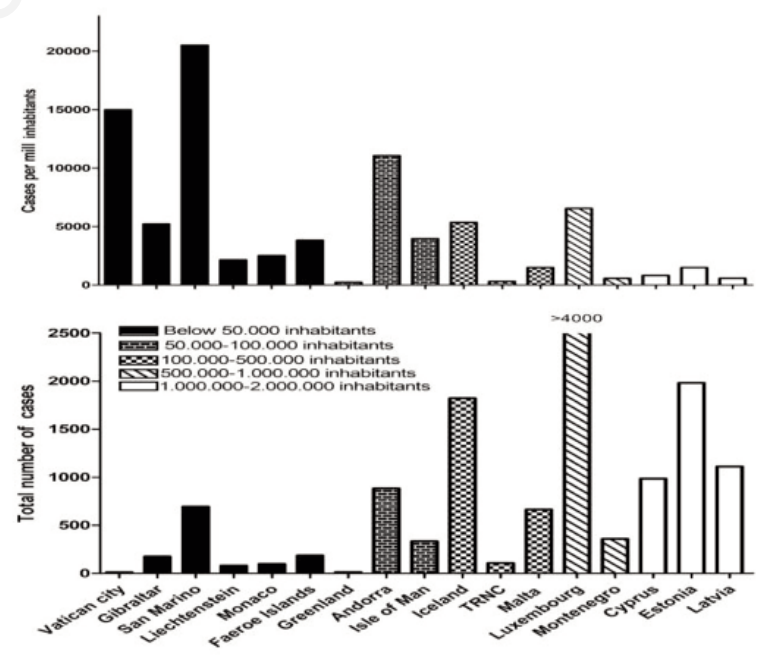

d

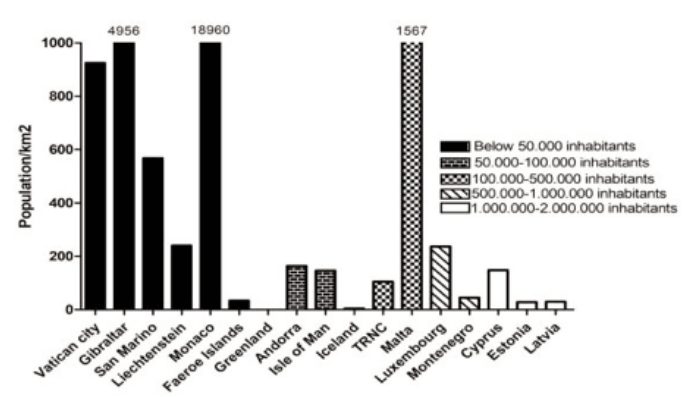

Figure 1. COVID-19 cases in the Turkish Republic of Northern Cyprus and comparison with other countries. 


\section{Discussion and Conclusions}

Lockdown was applied early basically within three days in TRNC and no new cases were achieved within 40 days. Only very isolated countries or countries able to close the access to their country accomplished similar results: the Isle of Man, Greenland, and Vatican City. The number of persons SARS-CoV-2 positive, the number of cases per million as well as the test applied per inhabitant did not have an impact on which country achieved zero cases $(\mathrm{p}>0.05)$. Importantly it seems that geographical isolation or strong bordering measures where the main factors to achieve zero cases beside the common measures applied. This is in accordance with the achievement in New Zealand which geographically is at a long distance from others. Furthermore, the other small European countries though not achieving zero cases were able to reduce the cases to a low number, controlling the spread. Early lockdown of a total society is not possible repeatedly solely due to the economic impact but local response to sporadic cases or clusters by finding, quarantining, may prevent further community transmission. However, it will have a substantial only if also sectors and communities ensure that every sector of government and society takes ownership of and participates in the response and in preventing cases through hand hygiene, respiratory etiquette, and individual-level physical distancing. Moreover, appropriate and proportionate restrictions on non-essential domestic and international travels needs should be considered with attention as they may be especially difficult in small countries with high income from tourism.

TRNC, which is the Northern part of Cyprus, had a relatively low mortality rate, but it was twice as high as in Cyprus which has the same environment and similar genetic background. This discrepancy is probably due to the differences in health care services, further uncovered by high mortality rate in the TRNC ICU unit of $80 \%$. Of course, as the absolute numbers of SARS-CoV-2 positive patients were low in TRNC a conclusion cannot yet be reached. Therefore, in countries with weaker health systems government measures as: isolation, physically distancing, staying at home except for essential journeys seem essential in order to block the transmission. This strategy is the only valid until and unless an effective vaccine is found, as a resurgence of infection may occur when these measures are relaxed. There is a need for more evidence about the effects of the different measures. Our observation has pointed at all the different lockdowns and contact rates that reached their goals to provide preventive measures during the coronavirus pandemic in TRNC as well as in the other countries [3].

In conclusion, TRNC was able to be a SARS-CoV-2 free country fast because of its geographical situation as well as of government regulations that were well accepted and applied by the population. This seems like an important result as there is a higher mortality risk in countries that would have difficulties overwhelming the health system; although largely applied measures as the number of testing seem due to achieve zero cases of less importance.

\section{Acknowledgements}

We would like to thank the government of TRNC for providing access to the COVID-19 data.

\section{References}

1. Worldometer.info [Internet]. International team of developers; c2020. Accessed on: 29th June 2020. Available from:

https://www.worldometers.info/coronavirus/

2. John Hopkins University [Internet]. Coronavirus Research Center; c2020. Accessed on: 29th June 2020. Available from: https://coronavirus.jhu.edu/map.html

3. West R, Michie S, Rubin GJ, Amlôt R. Applying principles of behaviour change to reduce SARS-CoV-2 transmission. Nat Hum Behav 2020;4:451-9. doi 10.1038/s41562-020-0887-9 